\title{
Thyroglossal Cyst Papillary Carcinoma: What Next Step must be done?
}

\author{
${ }^{1}$ Rajeev Gupta, ${ }^{2}$ Nariender K Mohindroo, ${ }^{3}$ Ramesh Azad, ${ }^{4}$ Jagdeep S Thakur
}

\begin{abstract}
Thyroglossal duct cysts (TGDCs) are usually midline structure of the neck. The coexistence of carcinomas in TGDCs is found rarely, with most being papillary carcinomas. Usually, the diagnosis is made postoperatively after excision of the cyst. Although the Sistrunk procedure is often regarded as adequate, various controversies exist concerning the need for thyroidectomy depending on histopathological findings. We are reporting the case of a 56-year-old man, diagnosed with papillary carcinoma within a TGDC, who underwent total thyroidectomy as has been recommended for differentiated papillary cancer.
\end{abstract}

Keywords: Papillary carcinoma, Thyroglossal cyst, Thyroid.

How to cite this article: Gupta R, Mohindroo NK, Azad R, Thakur JS. Thyroglossal Cyst Papillary Carcinoma: What Next Step must be done? Int J Phonosurg Laryngol 2017;7(1):23-26.

Source of support: Nil

Conflict of interest: None

\section{INTRODUCTION}

The thyroid gland embryologically descends from the foramen cecum to its location at the point below the thyroid cartilage. It leaves behind an epithelial tract known as the thyroglossal tract; usually this tract disappears during the 5 th to 10 th gestational weeks. Incomplete atrophy of the thyroglossal tract or retained epithelial cysts are considered as the basis for the origin of a thyroglossal duct cyst (TGDC). A thyroglossal remnant may be a cyst, a tract, duct, and fistula, or an ectopic thyroid within a cyst or duct. Failure of this tract to close predisposes to the formation of a thyroglossal cyst. ${ }^{1}$ A TGDC is the most common anomaly in the development of the thyroid gland. ${ }^{2}$ Seventy percent of midline masses diagnosed during childhood and $7 \%$ in adults are TGDCs. ${ }^{3}$ The condition is commoner in women than in men (1.5:1 ratio). About $1 \%$ of the TGDCs are histologically malignant, but the prognosis is generally good. ${ }^{4}$

\footnotetext{
${ }^{1}$ Resident, ${ }^{2}$ Professor and Head, ${ }^{3}$ Professor, ${ }^{4}$ Assistant Professor

${ }^{1-4}$ Department of ENT, Indira Gandhi Medical College, Shimla Himachal Pradesh, India

Corresponding Author: Rajeev Gupta, Resident, Department of ENT, Indira Gandhi Medical College, Shimla, Himachal Pradesh, India, Phone: +918894401387, e-mail: drrg87@ yahoo.co.in
}

Only $1 \%$ of thyroid carcinomas arise from a TGDC. ${ }^{5}$ Brentano in 1911 and Uchermann in 1915 are credited as being among the first to describe a neoplasm in a thyroglossal duct (TGD) remnant; the median age at presentation is 40 years and most patients are asymptomatic. $^{6}$

Definitive surgical management requires excision not only of the cyst but also of the path's tract. The strong association between the tract and the hyoid bone requires the simultaneous removal of the central portion of the hyoid bone to ensure the complete removal of the tract (Sistrunk procedure). Recurrence is unusual, except in cases with skin involvement or intraoperative cyst rupture.

There is still controversy regarding the decision to remove the thyroid gland in the case of a papillary carcinoma of the TGD. ${ }^{5}$ Thyroidectomy is recommended in cases where (a) the thyroid gland is found to be nodular, with a cold nodule in a thyroid iodine uptake scan; (b) enlarged lymph nodes are present, or (c) a history of neck irradiation exists. ${ }^{7}$

\section{CASE REPORT}

A 56-year-old male presented to ear, nose, throat head and neck surgery outpatient department of Indira Gandhi Medical College, Shimla, India, with complaint of midline swelling of neck for the last 4 years. It was gradually progressive in nature. Patient did not have any problem in breathing, swallowing, and no changes in quality of voice. There was no complaint of excessive sweating, feeling cold and heat. No history of loss of weight was found. Patient had history of diabetes mellitus type II for the last 2 years and was regularly taking medication (metformin, glimepiride) and had fairly controlled sugar levels.

On examination, there was about $3 \times 3 \mathrm{~cm}$ firm, nontender midline swelling present at the level of hyoid bone which moved on tongue protrusion. No lymph node and any swellings were noted clinically in the neck. On ultrasonography (USG) examination, there was anechoic cystic lesion of size $2.7 \times 2.3 \times 2 \mathrm{~cm}$ in strap muscle cranial to thyroid gland with possibility of thyroglossal cyst. There were fine internal echoes with amorphous eccentric calcified specs. Thyroid function tests showed euthyroid state. 
A fine needle aspiration was performed from the midline swelling. Aspiration smears showed colloid and benign follicular epithelial cells. These findings were suggestive of thyroglossal cyst. Sistrunk operation was performed for excision of thyroglossal cyst and submitted for histopathological examination (HPE). Grossly, the cyst was gray-brown, measured $3 \times 3 \times 2.5 \mathrm{~cm}$, and was filled with dark brown mucoid material. Microscopic examination showed a fibrous cyst wall with thyroid tissue and cholesterol clefts. The lining was thrown into papillary formation with psammoma body formation. The lining cells showed features of optical clearing, grooving, and intranuclear cytoplasmic inclusions. This focus measured less than $1 \mathrm{~cm}$. A HPE diagnosis of thyroglossal cyst with findings suspicious for papillary microcarcinoma was made (Figs 1 and 2). The histopathological findings were confirmed with immunohistochemistry studies which showed immunopositivity for CK 19 (Fig. 3) and immunonegativity for anti p63 and CD 56 (Figs 4 and 5).

A repeat USG was done, which showed both thyroid lobes being normal in shape, size, and echotexture. As patient was male and 56 years old, which kept him in high-risk group of differentiated thyroid cancers, total thyroidectomy was done. Final HPE report of thyroid specimen came to be benign thyroid parenchyma with macro- and microfollicles attenuated to hyperplastic follicular epithelium. There was no evidence of malignancy. Patient was attached with nuclear medicine department and regularly followed up till now.

\section{DISCUSSION}

In thyroid development TGDCs are common congenital anomalies, but TGD carcinomas are extremely rare, with $90 \%$ of them originating from thyroid remnants. The most common histological types of TGDC carcinoma are papillary carcinoma $(80 \%)$, mixed follicular-papillary carcinoma $(8 \%)$, squamous cell carcinoma $(6 \%)$, follicular carcinoma $(3 \%)$, adenocarcinoma, and various unclassified tumors $(3 \%) .{ }^{6}$ Medullary carcinoma has not been reported in TGDC and anaplastic carcinoma is rare. ${ }^{8}$ Their cause is unknown and there are no predisposing factors, i.e.,

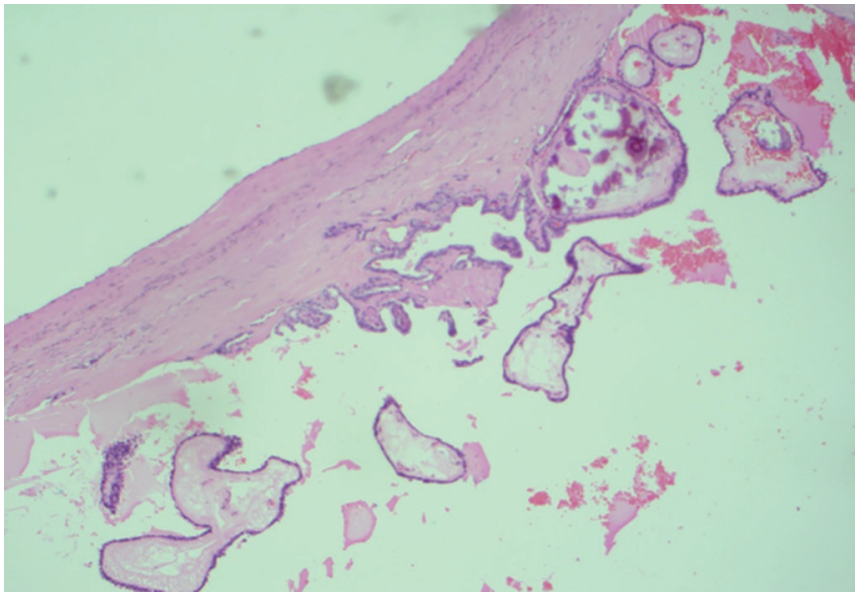

Fig. 1: Histopathological examination showing papillary carcinoma

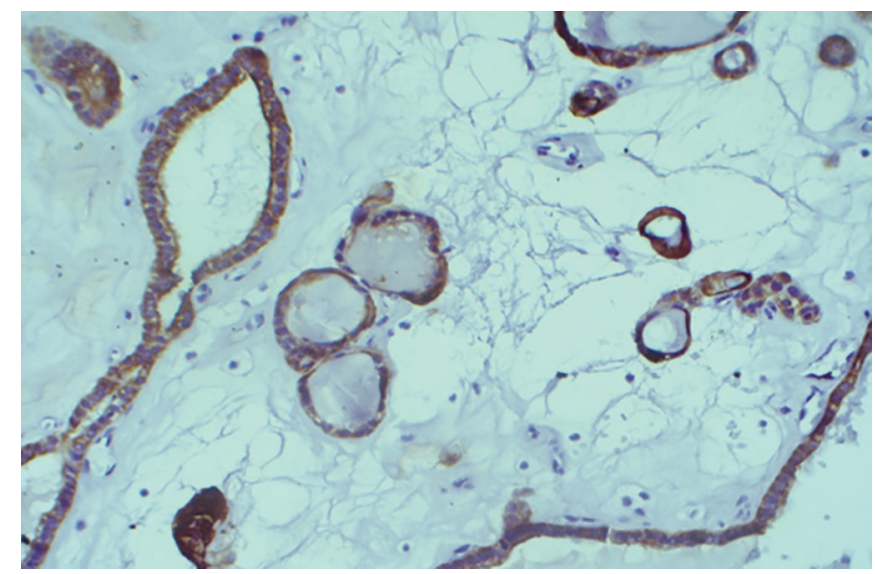

Fig. 3: CK 19 immunopositive

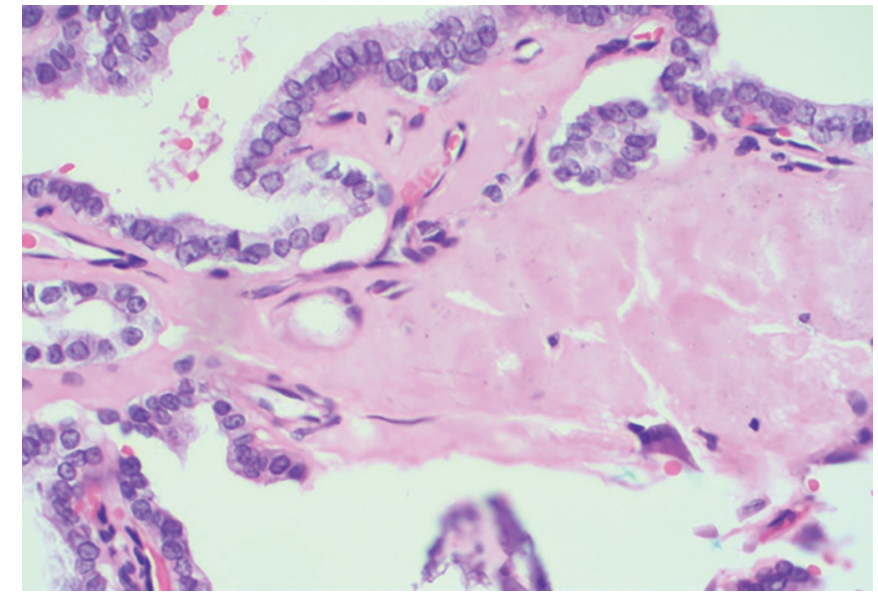

Fig. 2: Slide showing papillary carcinoma

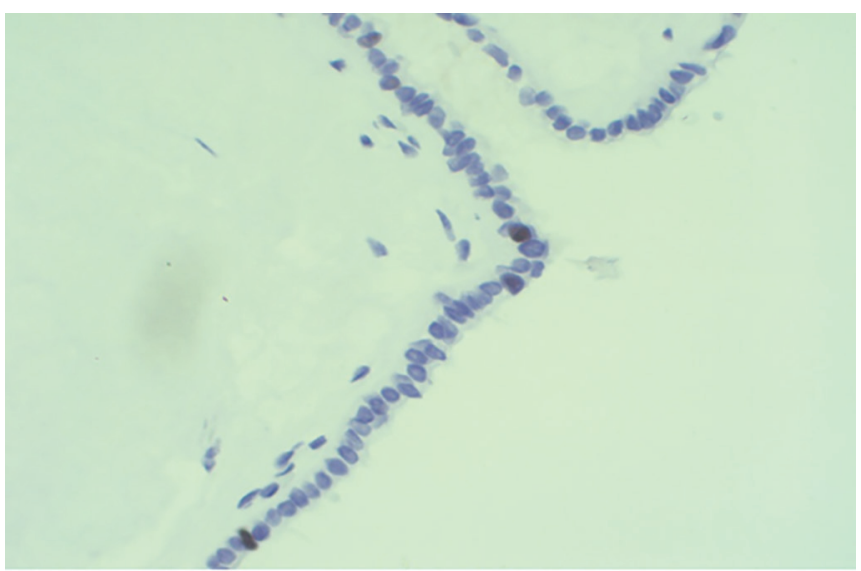

Fig. 4: p63 immunonegative 


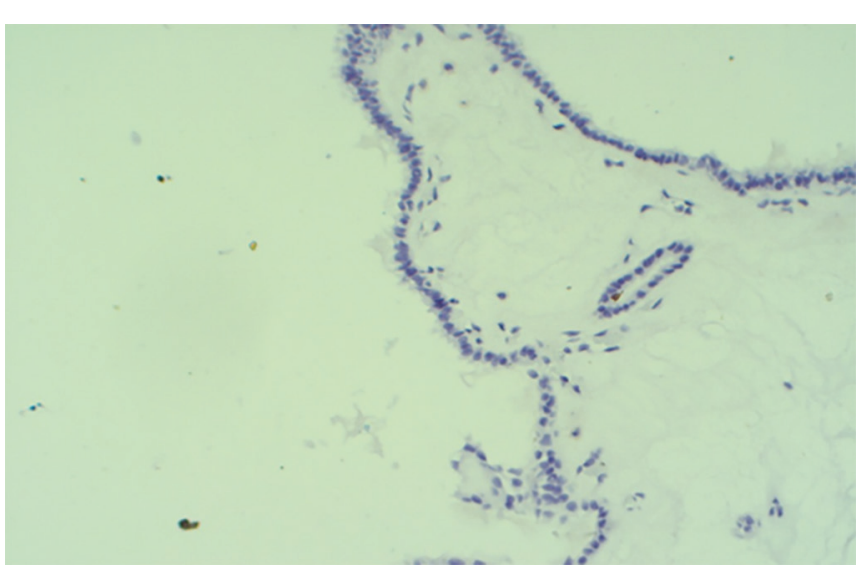

Fig. 5: CD56 immunonegative

neither clinical history nor physical examination can lead to a preoperative diagnosis. ${ }^{9}$

The etiology of the papillary carcinoma arising in a TDC is unclear but, generally, there are two theories which can explain this phenomenon, de novo origin and spread from a primary thyroid gland tumor. ${ }^{10}$

Firstly, the de novo theory is based on the fact that in $62 \%$ of cases, ectopic thyroid tissue can be identified histopathologically, and this is supported by the absence of a medullary carcinoma in the TGD as it arises from parafollicular cells. ${ }^{11}$ The second is the metastatic theory which suggests that thyroglossal cyst carcinoma is the result from metastatic from an occult primary thyroid gland, as papillary carcinoma is multifocal in nature. ${ }^{12}$

Mobini et $\mathrm{al}^{13}$ found that squamous cell carcinoma is probably the only true carcinoma of the TGD, since the other malignancies actually develop in ectopic thyroid tissue. Thus, squamous cell carcinoma can be considered the only primary thyroglossal cyst tumor, being very rare and having a poor prognosis with a mortality rate of 30 to $40 \%{ }^{14}$

Most authors support the theory of primary de novo origin by the ectopic thyroid nests of the cyst wall rather than the metastatic spread from a primary thyroid gland tumor through the duct from the thyroid carcinoma. The other theory explains synchronous occurrence of TGDC carcinoma and thyroid carcinoma, which are reported to be even rarer, as multifocal tumor. ${ }^{15}$

Park et $\mathrm{l}^{16}$ proposed criteria based on HPE. A primary carcinoma of the TGD should demonstrate that the duct or cyst has an epithelial lining with normal thyroid follicles within the cyst wall and normal thyroid tissue adjacent to the tumor and thyroid gland showing sign of primary carcinoma.

Malignant TGDCs are commonly mistaken from benign TGDCs because of the indistinguishable mass presence at the anterior neck. Preoperative evaluation of TGDC includes head and neck examination, palpation of thyroid gland, and imaging techniques. Malignancy cannot usually be diagnosed preoperatively by imaging diagnostic techniques (ultrasound, scintigraphy, and computed tomography). Furthermore, fine needle aspiration biopsy can only give a correct result in about 53 to $66 \%$ of the cases..$^{16}$ The diagnosis of carcinoma arising in TGDC is based on pathological examination of the cyst. In most of the cases reviewed in the literature, the malignancy was not suspected before surgery but during surgery or from definitive pathological samples. ${ }^{17}$

Multicentricity and multifocal growth are common in papillary thyroglossal carcinomas, as a second malignant lesion is present in $10 \%$ of cases with thyroid cancer. ${ }^{6}$ Conservative management of papillary thyroid cancer is indicated only in low-risk patients who are female and younger than 40 years, with no invasion of the capsule and a low-grade tumor of $<1 \mathrm{~cm}$ in size. We recommend no additional treatment to the Sistrunk procedure for pure thyroglossal carcinoma of squamous cell origin. In contrast, for differentiated thyroid malignancy in a thyroglossal cyst, total thyroidectomy is indicated, whether or not the thyroid is involved clinically or radiologically. In the case of large tumors $>1 \mathrm{~cm}$, invasion through the duct cyst wall or suspect foci in the thyroid gland, a total thyroidectomy followed by $\mathrm{I}^{131}$ ablation was performed, and thyroid-stimulating hormone suppression is the most frequently proposed treatment. ${ }^{18}$

The surgical procedure which is commonly performed for a TGDC is a surgery called Sistrunk's procedure. This procedure consists of removal of the TGDC, the medial segment of the hyoid bone, and a core of tissue around the duct to open into the oral cavity at the foramen cecum, although some surgeons consider the Sistrunk's procedure to be adequate if histological examination does not show extra cystic extension. ${ }^{19}$ Regarding cervical lymph nodes, even if these are not palpable, clinically frozen sections are considered to be mandatory. Radical or modified radical neck dissection is indicated only in the presence of positive lymph nodes. ${ }^{6}$

The prognosis for papillary TGDC carcinoma is excellent, with occurrence of metastatic lesions in $<2 \%$ of cases. ${ }^{20}$

\section{CONCLUSION}

The diagnosis of TGD carcinoma can be missed due to its rarity. Surgeons must be aware and include this entity while examining a patient with a neck mass especially located around hyoid bone with physical examination suspected malignancy. Considering the embryological development of the thyroid, the ideal treatment for the malignancy of the TGD consists of total thyroidectomy too. 


\section{REFERENCES}

1. Peretz A, Leiberman E, Kapelushnik J, Hershkovitz E. Thyroglossal duct carcinoma in children: case presentation and review of the literature. Thyroid 2004 Sep;14(9):777-785.

2. Vera-Sempere F, Tur J, Jaén J, Perolada JM, Morera C. Papillary thyroid carcinoma arising in the wall of a thyroglossal duct cyst. Acta Otorhinolaryngol Belg 1998;52(1):49-54.

3. Yang YJ, Haghir S, Wanamaker JR, Powers CN. Diagnosis of papillary carcinoma in a thyroglossal duct cyst by fine-needle aspiration biopsy. Arch Pathol Lab Med 2000 Jan;124(1): 139-142.

4. Joseph TJ, Komorowski RA. Thyroglossal duct carcinoma. Hum Pathol 1975 Nov;6(6):717-729.

5. Dedivitis RA, Guimarães AV. Papillary thyroid carcinoma in thyroglossal duct cyst. Int Surg 2000 Jul-Sep;85(3):198-201.

6. Weiss SD, Orlich CC. Primary papillary carcinoma of a thyroglossal duct cyst: report of a case and literature review. Br J Surg 1991 Jan;78(1):87-89.

7. Kazemi M, Assadi M, Kazemi AA, Ghazvini LA. Primary papillary carcinoma in a thyroglossal duct cyst. Hell J Nucl Med 2006 Jan-Apr;9(1):39-40.

8. Heshmati HM, Fatourechi V, Heerden JA, Hay ID, Goellner JR. Thyroglossal duct carcinoma: report of 12 cases. Mayo Clin Proc 1997 Apr;72(4):315-319.

9. Buchino JJ, Fallat ME, Montgomery VL. Pathological case of the month: papillary carcinoma of the thyroid in a thyroglossal duct remnant. Arch Pediatr Adolesc Med 1999 Sep;153(9): 999-1000.

10. Balalaa N, Megahed M, AlAshari M, Branicki F. Thyroglossal duct cyst papillary carcinoma. Case Rep Oncol 2011 Jan 29;4(1):39-43.
11. Hilger AW, Thompson SD, Smallman LA, Watkinson JC. Papillary carcinoma arising in a thyroglossal duct cyst: a case report and literature review. J Laryngol Otol 1995 Nov;109(11): 1124-1127.

12. Tew S, Reeve TS, Poole AG, Delbridge L. Papillary thyroid carcinoma arising in thyroglossal duct cyst: incidence and management. Aust NZ J Surg 1995 Oct;65(10):717-718.

13. Mobini J, Krouse TB, Klinghoffer JF. Squamous cell carcinoma arising in a thyroglossal duct cyst. Am Surg 1974 May;40(5):290-294.

14. Boswell WC, Zoller M, Williams JS, Lord SA, Check W. Thyroglossal duct carcinoma. Am Surg 1994 Sep;60(9): 650-655.

15. Pribitkin EA, Friedman O. Papillary carcinoma in a thyroglossal duct remnant. Arch Otolaryngol Head Neck Surg 2002 Apr;128(4):461-462.

16. Park MH, Yoon JH, Jegal YJ, Lee JS. Papillary thyroglossal duct cyst carcinoma with synchronous occult papillary thyroid microcarcinoma. Yonsei Med J 2010 Jul;51(4):609-611.

17. Kandogan T, Erkan N, Vardar E. Papillary carcinoma arising in a thyroglossal duct cyst with associated microcarcinoma of the thyroid and without cervical lymph node metastasis: a case report. J Med Case Rep 2008 Feb 8;2:42.

18. Kristensen S, Juul A, Moesner J. Thyroglossal cyst carcinoma. J Laryngol Otol 1984 Dec;98(12):1277-1280.

19. Ali MA, Abussa A, Hashmi H. Papillary thyroid carcinoma formation in a thyroglossal cyst. A case report. Libyan J Med 2007 Sep 1;2(3):148-149.

20. Aghaghazvini L, Mazaher H, Sharifian H, Aghaghazvini S, Assadi M. Invasive thyroglossal duct cyst papillary carcinoma: a case report. J Med Case Rep 2009 Dec 1;3:9308. 